\title{
Measuring health literacy in emergency departments
}

\author{
Muhammad Alqudah ${ }^{1}$ Maree J ohnson ${ }^{2}$, Leanne Cowin ${ }^{3}$, Ajesh George $^{4}$ \\ 1. School of Nursing \& Midwifery, University of Western Sydney, Sydney, Australia. 2. Centre for Applied Nursing Research, \\ South Western Sydney Local Health District, and School of Nursing \& Midwifery, University of Western Sydney, Sydney, \\ Australia. 3. Nursing School of Nursing and Midwifery, University of Western Sydney, Sydney, Australia. 4. Centre for \\ Applied Nursing Research, University of Western Sydney and South Western Sydney Local Health District, Sydney, \\ Australia.
}

Correspondence: Maree Johnson. Addredss: Centre of Applied Nursing Research, locked bag 7103, Liverpool BC NSW 1871, Sydney, Australia. Email: m.johnson@uws.edu.au

Received: June 5, 2013

DOI : $10.5430 /$ jnep.v4n2p1
Accepted: July 4, 2013

URL: http://dx.doi.org/10.5430/jnep.v4n2p1

\section{Abstract}

Background: Literacy and health literacy are important concepts that are related to how important health care messages are understood by patients. Emergency nurses are engaged in health promotion and require an understanding of the patient's health literacy. To assist emergency nurses in assessing a patient's level of health literacy a series of valid and reliable health literacy measurement tools have been presented. The aim of this paper is to nominate one of these tools to be used by emergency nurses in testing individual and group levels of health literacy.

Methods: Databases searched included Scopus, Science direct, PubMed, PsycINFO and Educational Resources Information Center (ERIC). Included articles were published between 1990 and 2011, English language only, and articles that discussed word recognition tools and tools that take five minutes or less to administer resulting in sixteen articles.

Results: The Rapid Estimate of Adult Literacy in Medicine-Short Format (REALM-SF) has been used successfully within an emergency setting to identify patients' level of health literacy and to supply appropriate health information. This tool was found by nursing staff to be easily administered, and more acceptable when used in private areas. However, further research within varying age groups is recommended.

Conclusion: Most of the available tools are related to each other and have the ability to measure varying levels of health literacy. The REALM-SF is a simple quick approach to measuring health literacy in busy clinical settings. Emergency nurses require training in administering these tests in a non-threatening and accurate manner.

\section{Key words}

Literacy, Health literacy, Measures, Emergency, Nursing

\section{I ntroduction}

Health literacy, or how health consumers understand and act upon health information, has become a priority in the delivery of health care, as consumers with limited health literacy skills experience poorer health outcomes ${ }^{[1]}$ and are often high users of health services ${ }^{[2,3]}$. Literacy and health literacy are associated concepts. Literacy has been defined as the ability to read, write and speak with a certain level of proficiency ${ }^{[4]}$, while health literacy is defined as "the degree to which individuals have the capacity to obtain, process and understand basic health information and services needed to make 
appropriate health decisions" ${ }^{[5]}$. Health literacy assessment has been demonstrated as being as important as patient vital signs and is proposed as the sixth vital sign ${ }^{[6]}$.

The extent of the health literacy problem is only now becoming known within countries with increased proportions of their population from culturally and lingustically diverse backgrounds. Surveys across various countries such as the National Assessment of Adult Literacy (NAAL) ${ }^{[7]}$ have revealed unexpected figures, with one third of Americans being found to have limited health literacy ${ }^{[8]}$ while approximately $20 \%$ of the British population are illiterate ${ }^{[9]}$. In Canada, $65 \%$ of the population lack basic health literacy ${ }^{[10]}$, and more than $60 \%$ of Australians are reported as having inadequate health literacy skills ${ }^{[1]}$. According to an international report, Australian teenagers skills in reading, writing and arithmetic were found to be much worse now than they were 10 years ago ${ }^{[12]}$ indirectly influencing the health literacy level of the general population.

Poor health literacy skills result in potential inappropriate use of a health facilities, increased hospitalisations, poorer health outcomes and increased costs of health care ${ }^{[1,3,13]}$. Emergency Departments (ED) are often the first point of contact for patients. This busy clinical setting is often managing the delivery of important health information. For patients with limited health literacy there is an increased demand for clarification of instructions for these patients by busy ED staff ${ }^{[14]}$. Other aspects of the ED environment such as ED overcrowding, longer waiting times, decreased ED staff productivity and increased ED staff frustration may also occur ${ }^{[2,14]}$. Although the measurement of health literacy may be relevant to all nursing settings, this paper explores the measurement of health literacy within the ED. This focus was highlighted as part of a clinical trial on fever management education for parents with limited health literacy.

Given the extent of the problem of limited health literacy within Australia (the location of the study) and other countries, we believe that nurses and other health professionals should assess patients' level of health literacy prior to delivering any health information. Nurses continue to assume that health messages are being received by patients, with no knowledge of whether the health information is delivered in a manner that is understood. By assessing the level of health literacy, this information can be tailored or modified to increase the likelihood of the information being received ${ }^{[15]}$. This is particularly relevant to ED nurses since they are continuously and directly involved in patient consultation. Emergency nurses can easily assess their patient's level of health literacy, as there are a range of suitable tools or approaches that could be used in practice.

\section{Aim}

The aim of this study is to use a systematic approach to critically analyse tools to measure health literacy that would be suitable for use by emergency nurses. Specific features of these tools to be considered included: advantages, disadvantages, selected psychometric properties of the tools such as reliability and validity, and the time needed to administer and score the patient.

\section{Literature review}

Both informal and formal approaches to measuring health literacy exist. A patient's level of health literacy can be measured in an informal way simply by observing their behaviour. For example, observing a patient's ability to fill out forms correctly, such as misspelling or misinterpretation can indicate poor literacy and most likely poor health literacy ${ }^{[4]}$. However, it has been argued that this is not efficient since the patient may feel shy or embarrassed ${ }^{[16]}$ and it is not a formal method of measurement. Formal methods are more organised, created for research and clinical purposes, and are more suitable for testing individual and group levels of health literacy. The creation of formal tools is based on systematic testing, using large sample sizes and through confirmation of the validity and reliability of the instruments ${ }^{[17,18]}$.

Various tools have been used to measure health literacy among populations and within clinical settings including computerised tools, language-specific tools and disease specific tools. Instruments such as the Adult Literacy and Life Skills Survey (ALLS) in Australia ${ }^{[11]}$, the Health Activities Literacy Scale (HALS) in America ${ }^{[17]}$, and the International Adult 
Literacy and Skills Survey (ALL) in Canada (2003) ${ }^{[10]}$ have been used to assess populations. Other instruments include: the health literacy screening questions ${ }^{[1]}$, The Functional Health Literacy in Adults (TOFHLA) ${ }^{[19]}$, Rapid Estimate of Adult Literacy in Medicine (REALM) ${ }^{[16,18,20-22]}$, The Medical Achievement Reading Test (MART) ${ }^{[23]}$, the Newest Vital Sign (NVS) ${ }^{[24]}$, a single item health literacy screening question ${ }^{[25]}$, the Slosson Oral Reading Test (SORT) ${ }^{[26,27]}$, and the Wide Range Achievement Test (WRAT) ${ }^{[28,29]}$.

Some tools have been developed for computer use to facilitate the health screening process such as English-Spanish Talking Touchscreen (TT) ${ }^{[30]}$ and the Health Literacy Assessment Using Talking Touchscreen Technology (Health LiTT) ${ }^{[31]}$. However, researchers argue that the use of these tools can be limited since people with low health literacy skills concurrently also have poor computer skills ${ }^{[30]}$. Other tools have been designed to test the level of understanding of presented material by media such as the Media Health Literacy (MHL) tool ${ }^{[32]}$.

A systematic review by Berkman, et al. ${ }^{[13]}$ highlighted tools using word recognition tests and comprehension assessment. Many of these tools are language specific as in the Hebrew Health Literacy Test (HHLT) ${ }^{[33]}$ or the Short Assessment of Health Literacy for Spanish Adults (SAHLSA) ${ }^{[34]}$. Some tools are disease or focus specific such as the Literacy Assessment for Diabetes (LAD) or Nutritional Literacy Scale (NLS) ${ }^{[35]}$. Other tools reflect literacy as in Subjective Literacy Screener or numeracy only, as in Lipkus Numeracy Test, Schwartz and Woloshin Numeracy Test, and Subjective Numeracy Scale (SNS) ${ }^{[13]}$.

Although the above mentioned tools are valid and reliable, choosing an appropriate tool to be used in the emergency department requires some consideration as this setting has specific features. Emergency departments operate 24 hours, accept both urgent and non-urgent cases, and have direct contact with patients ${ }^{[14,36]}$. For this reason tools that may be used by nurses need to be easy to administer, time efficient and reliable. Due to the substantial number of tools that are available, the authors believe that only a critical analysis of existing tools using a systematic approach can provide direction on the appropriate tools for use in the emergency setting.

\section{Method of review: Search strategy}

An extensive search of the literature was conducted to identify tools that measure health literacy. The search technique was a combination of a computer database search and hand search for unpublished literature. The search terms included: literacy, health literacy, tools, measurement, and a combination of these words. During the literature search, a variety of terminologies were used and the spelling of key words was considered to aid the identification of relevant literature. The combination of key words were thoroughly researched using "Boolean" operators (or and not), truncation, phrase searching, and MeSH (Medical Subject Heading) keywords were also used in the search strategies. Databases searched included Scopus, Science direct, PubMed, PsycINFO and Educational Resources Information Center (ERIC), and the search was limited to articles that were published between 1990 and 2011. The authors have included the original source of the instrument where required, which may be beyond the range of dates noted in the search.

\section{Inclusion criteria}

Tools were considered for inclusion based on three criteria: tools using word recognition procedures, tools taking a maximum of five minutes administration time and tools with demonstrated concurrent validity (correlation between the levels identified by the comparison instruments) with other well validated tools ${ }^{[22,26]}$. Word recognition tests are more acceptable as individuals who have difficulty in reading will most likely have difficulty comprehending written information ${ }^{[5]}$. In addition, there is a strong association between an individual's reading ability level and their level of health literacy ${ }^{[6,16,35,37]}$. Tools included in the review needed to be time efficient and could be undertaken in five minutes or less. The five minute duration was based on the time required to administer the most commonly used tool to measure health literacy level; that is the revised version of WRAT (WRAT-R). Only publications in English were included in this review. 
The references and abstracts identified from the search were imported into Endnote Version X4 software. Duplicate references were removed and the title and abstract of the remaining studies were assessed against the inclusion criteria.

\section{Results}

\section{I dentification of studies}

The broad search strategy used identified 346 articles in all. A majority of the articles were removed after reviewing the abstract since they focused on descriptive papers relating to literacy and health literacy rather than the measurement of health literacy, resulting in 109 articles. Only articles in English with full text were retrieved, resulting in 101 articles. Sixteen articles that met the inclusion criteria were included in this review (see Figure 1).

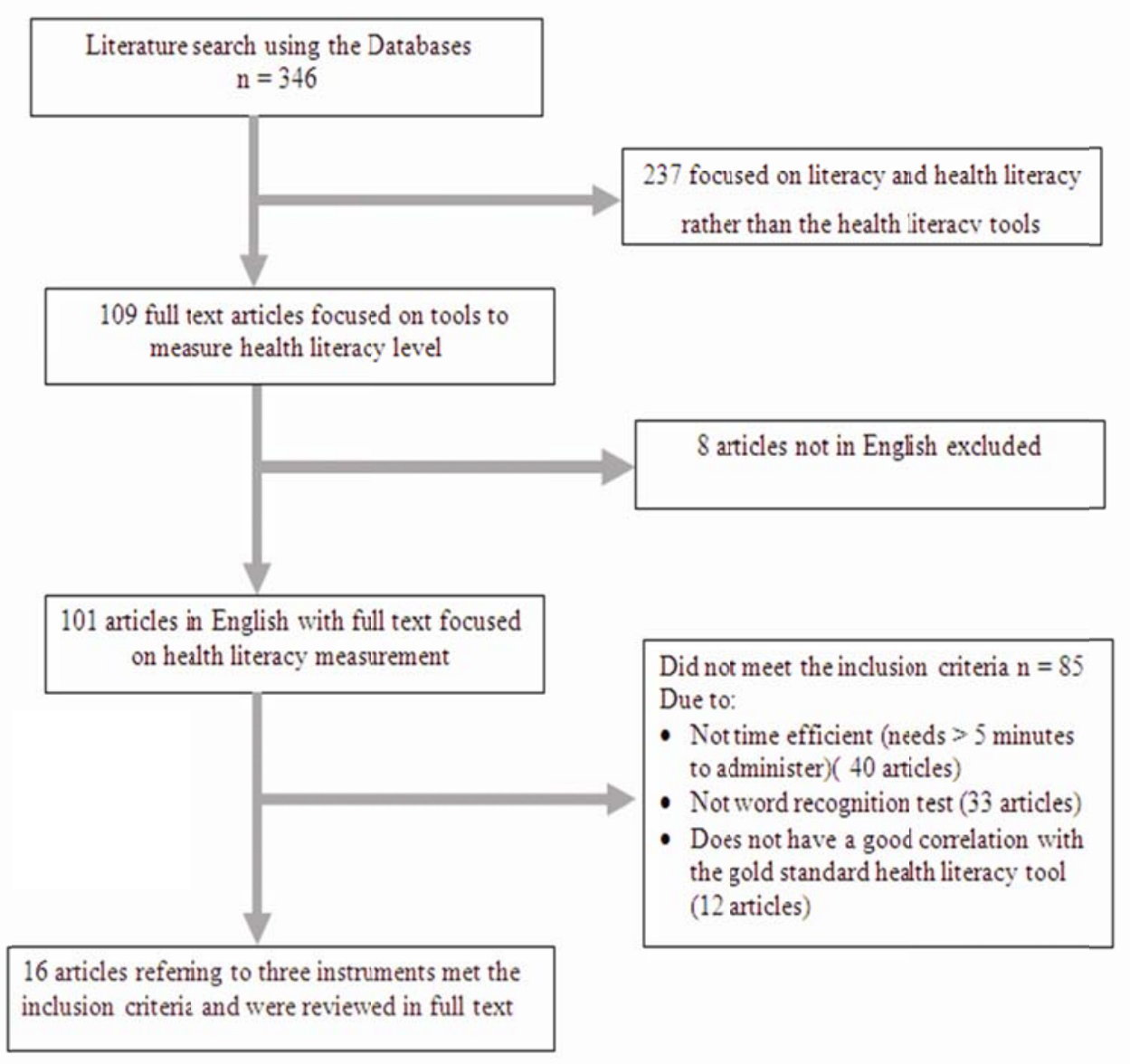

Figure 1. Methodology: Inclusion and Exclusion Criteria

The most common health literacy screening tools available and frequently reported within the literature are NVS, REALM, TOFHLA, and WRAT ${ }^{[5,26]}$. Although TOFHLA is one of the most commonly used health literacy screening tool, this tool along with its shortened format (TOFHLA-SF) have been excluded from this review because they are too long to administer (TOFHLA -22 minutes, TOFHLA-SF- 10 minutes). The Newest Vital Sign (NVS) ${ }^{[24]}$, the Rapid Estimate of Adult Literacy in Medicine -Short Format (REALM-SF) ${ }^{[20]}$, and the Wide Range Achievement Test Revised (WRAT-R) or WRAT version 3 (WRAT-3) ${ }^{[29]}$, are the shortest health literacy screening tools found in the literature and have been examined extensively for their psychometric properties and their ease of use for consideration within the emergency setting (see Table 1). 
Table 1. Features of the Reviewed Tools (Summary)

\begin{tabular}{|c|c|c|c|}
\hline Criteria & NVS-E & REALM-SF & WRAT-3 \\
\hline Number of Items & 6 nutritional questions & 7 medical words & $\begin{array}{l}\text { For the reading subtest. } \\
\text { ( } 15 \text { letters } 42 \text { words) }\end{array}$ \\
\hline Age group & 18 years or older & Adolescence & Between 5 and 74 years \\
\hline Time required & Up to 3 minutes & $<1$ minute & 3 to 5 minutes \\
\hline Scoring & $\begin{array}{l}\geq 2=\text { inadequate } \mathrm{HLL} \\
3=\text { marginal } \mathrm{HLL} \\
\leq 4=\text { adequate } \mathrm{HLL}\end{array}$ & $\begin{array}{l}\text { Total correct } \\
0-3=\text { inadequate HLL } \\
4-6=\text { marginal HLL } \\
7=\text { adequate HLL }\end{array}$ & $\begin{array}{l}\text { Uses a row of scores from } 1 \text { to } 57 \text { converted to } \\
\text { grade-equivalent reading levels }\end{array}$ \\
\hline Reliability & $\begin{array}{l}\text { Cronbach's } \alpha=0.76 \text { in } \\
\text { English version }\end{array}$ & $\begin{array}{l}\text { Strong test-retest reliability } \\
\text { coefficient }(r=0.97)\end{array}$ & $\begin{array}{l}\text { Strong test-retest reliability coefficient }(r= \\
0.91 \text { to } 0.98) \text {. }\end{array}$ \\
\hline Validity & $\begin{array}{l}\text { Demonstrates moderate } \\
\text { correlation with } \\
\text { TOFHLA. Criterion } \\
\text { validity }(r=0.59 \text {, } \\
p<.001)\end{array}$ & $\begin{array}{l}\text { Excellent agreement between } \\
\text { REALM-SF and REALM } \\
\text { (Numbers). Strong correlations with } \\
\text { SORT-R }(0.96, p<.001) \text {, PIAT-R } \\
(0.97, p<.001) \text {, and WRAT-R }(0.88 \text {, } \\
p<.001)\end{array}$ & $\begin{array}{l}\text { Moderate to strong correlation with the } \\
\text { California Test of Basic Skills and Stanford } \\
\text { achievement test, } 0.72 \text { and } 0.87 \text { respectively. }\end{array}$ \\
\hline Cost & Free & $\$ 10.00^{[26]}$. & $\$ 95.00^{[26]}$. \\
\hline Advantages & $\begin{array}{l}\text { Available to measure, } \\
\text { maths, reading, and } \\
\text { comprehension. } \\
\text { Available in two } \\
\text { languages. }\end{array}$ & $\begin{array}{l}\text { Time efficient, contains only health } \\
\text { words. }\end{array}$ & Measures reading, spelling, and mathematics. \\
\hline Disadvantages & $\begin{array}{l}\text { Designed for literacy } \\
\text { skills rather than health } \\
\text { literacy skills. }\end{array}$ & $\begin{array}{l}\text { Unable to distinguish between } \\
\text { patients with ninth grade reading } \\
\text { level and above. }\end{array}$ & $\begin{array}{l}\text { Comprehension not tested. } \\
\text { Words not chosen from health care context, } \\
\text { contains some difficult terms and issues. }\end{array}$ \\
\hline
\end{tabular}

Note. $\mathrm{HLL}=$ Health Literacy level.

\section{Newest Vital Sign ( NVS)}

The NVS was first introduced in 2005 by Weiss and co-workers to develop a quick and accurate screening tool for low literacy people. This test is available in two languages, English (NVS-E) and Spanish (NVS-S) ${ }^{[24]}$.

In this test patients are required to answer six questions based on the information provided on a nutrition label. Questions are then scored whether correct or incorrect. The scores range between zero and six: four or more correct answers $=$ adequate literacy, three $=$ marginal literacy, and two or less $=$ inadequate literacy ${ }^{[24,38]}$. This tool is designed for literacy skills rather than health literacy skills and it takes approximately three minutes to administer.

NVS was tested within the south west of the United States of America (US) which has high numbers of English and Spanish speakers ${ }^{[24]}$ and has been used in large surveys of 2824 Australians in $2009^{[38]}$. The NVS is used by researchers in literacy and health literacy measurement because it measures maths, reading, and comprehension skills as well as abstract reasoning ${ }^{[4]}$. The NVS demonstrated a strong correlation and sensitivity with the TOFHLA ${ }^{[24]}$. The internal consistency (Cronbach's $\alpha=0.76$ ) and criterion validity of the English version of the NVS was satisfactory $(r=0.59)^{[4,24]}$, (see Table 1). The NVS is an internationally recognised tool designed to suit people aged from 18 years or older. This tool can be accessed at no cost from: http://www.pfizerhealthliteracy.com/asset/pdf/NVS_Eng/files/nvs_flipbook_english_final.pdf ${ }^{[39]}$.

\section{Rapid Estimate of Adult Literacy in Medicine (REALM-SF)}

The Rapid Estimate of Adult Literacy in Medicine (REALM) health literacy measurement tool was first introduced in 1991 by Davis and co-workers, includes 125 words, and requires three to five minutes to administer and score ${ }^{[18]}$. The REALM was re-constructed again in 1993 to contain 66 words and can be undertaken in less than two minutes. It was 
initially tested in African American and Caucasian populations ${ }^{[20]}$. Being the most common method used in the health care context, the REALM is time efficient, and contains only health words ${ }^{[4,22]}$. This tool has been revised many times thereby producing different versions such as the REALM-R in Bass III et al. ${ }^{[16]}$, a new version of REALM (REALMTeen) ${ }^{[22]}$, and REALM short form (REALM-SF) ${ }^{[20]}$. Only the REALM-SF is explored here because it is the most usable form found in the research studies. REALM-SF takes less than a minute to administer and score. REALM-SF also has a strong correlation with other literacy tools such as WRAT-R (concurrent validity).

The words in the REALM-SF are arranged in one column based on the difficulty of the word and number of syllables. The test is usually carried out by asking patients to pronounce the words in a loud voice starting with the first word. However, if patients find it difficult to read a word, they are asked to try again or say "skip" and then move on to the next word. If patients are unable to continue, they are asked to look at the list of the words and read as many as they can from the remaining words. The level of health literacy is determined based on the number of words pronounced correctly, a total correct 0-3 indicates inadequate level of health literacy, 4-6 indicates marginal health literacy and seven indicates an adequate health literacy level. REALM has been designed for people within the adolescent aged group. However, REALM-SF has been validated and tested on varying age groups ${ }^{[20]}$. The full version of REALM costs $\$ 10.00$ to purchase ${ }^{[26]}$.

The contents of REALM were extracted from educational materials and forms that were used in Louisiana State University Hospital Clinic ${ }^{[18]}$. Both the REALM and the revised versions, demonstrate high correlations with earlier commonly used tools, such as SORT-R $(0.96 p<.001)$, the Peabody Individual Achievement Test-Revised (PIAT-R) PIAT-R $(0.97, p<.001)$, as well as WRAT-R $(0.88, p<.001)^{[4,20,22,26]}$. In addition, the REALM demonstrates face validity in measuring patient's level of health literacy and can be undertaken in public health clinics ${ }^{[4,18]}$. The REALM has high test-retest reliability $(r=0.97, p<.001)^{[18,22,26]}$ (see Table 1$)$.

\section{Wide Range Achievement Test - Revised}

The Wide Range Achievement Test (WRAT), was introduced for the first time in 1946 by Jastak and Bijou, and was revised in 1984 to WRAT-R by Jastak and Wilkinson ${ }^{[29,40]}$. WRAT-R was also modified in 1993 and renamed the WRAT version 3 (WRAT-3) ${ }^{[29,40]}$. WRAT-3 is the most frequently used version of the WRAT tool according to the literature ${ }^{[26,29]}$. The WRAT-3 was designed to measure basic skills of reading, spelling, and mathematics for general literacy skills in the shortest time ${ }^{[26]}$. The main WRAT was tested in seven different US states, in diverse cultural groups including Caucasian, Afro-Americans and Hispanics. It is the oldest and the second most common health literacy tool used for both patients and their caregivers aged between five years and 74 years ${ }^{[26,28]}$. The test contains two sections: a letter test and a word test. The letter section of the test requires the patient to pronounce 15 letters, while the word reading section requires the patient to pronounce 42 words. The words in this test are arranged in ascending order of difficulty. The test takes approximately three to five minutes to administer and score.

The WRAT-3 test can be marked by using the raw scores, which range from 1 to 57, and can be converted to gradeequivalent reading levels ${ }^{[16,22,26]}$. The main limitation of the WRAT-3 is that it contains some difficult terms such as assuage, terpsichorean, and epithalamion. In spite of this, WRAT-3 is the second most common word recognition test used in medical settings ${ }^{[16,22]}$. This test costs $\$ 95.00$ to purchase ${ }^{[26]}$.

Concurrent validity of WRAT-3 is supported through a strong correlation with the California Test of Basic Skills and the Stanford achievement test of 0.72 and 0.87 respectively. WRAT-3 has demonstrated high test-retest reliability with scores ranging from 0.91 to $0.98^{[16,26]}$ (see Table 1).

\section{Discussion}

The relationship between patients' health literacy level and health outcomes has been established ${ }^{[3,25]}$. Emergency nurses play a significant role in patient education ${ }^{[41]}$, requiring the use of appropriate forms of health instruction, potentially 
modified for varying health literacy levels. Knowing a patient's level of health literacy can help the ED nurse choose and design suitable educational materials that match the patient's level of understanding ${ }^{[4]}$, and use effective communication strategies that draw the patient's attention to any delivered instructions ${ }^{[14]}$. Health care professionals need to be aware of these health literacy tools, how to use them, and how to gauge a patient's level of health literacy.

Although many instruments exist to measure both literacy and health literacy, only limited numbers have demonstrated extensive use in health settings with adequate psychometric properties. Some of these instruments are commonly used in practice and frequently reviewed in the literature, for example the REALM and the WRAT ${ }^{[16,26]}$. A criticial analysis of three key instruments NVS, REALM-SF, and the WRAT-3 has highlighted some important differences and similarities. All the tools are word recognition tests and useful when used in the health care context.

There is limited evidence of the psychometric properties of some of the tools as in the WRAT-R/3. The REALM-SF and the WRAT-3 have reported satisfactory inter-rater reliability and the NVS has demonstrated internal-consistency. Validity testing for all the instruments was limited with REALM-SF noting good face validity ${ }^{[22]}$ and WRAT-3 describing a process of content validation ${ }^{[16,26]}$. Further confirmation of the psychometric properties of these instruments is recommended in diverse populations.

One of the most commonly used tools in the health care setting is the REALM as it is efficient and relevant to health. Two short revised versions of the REALM are available in the literature; the REALM-R and the REALM-SF ${ }^{[16,20]}$. The REALM-SF has been identified from this analysis as the preferred instrument to be used in an ED for individual and group assessment of health literacy. This tool has been chosen due to its contemporary revision and demonstrated concurrent validity with other tools, with fewer limitations than REALM-R, and being time efficient to administer $(<1$ minute). Although, REALM-R and REALM-SF are quite similar, the REALM-R has only been tested on populations that are relatively well educated and on elderly patients ${ }^{[20]}$. Consequently, Arozullah and colleagues argue that the applicability of the REALM-R has not been established for people with low literacy.

REALM-SF will give ED nurses a simple approach to measuring health literacy in varying situations. The REALM-SF can be used by ED nurses to measure a patient's level of health knowledge in both urgent and non-urgent situations, within waiting areas, treatment rooms, diagnostic areas, during medical consultation, or while waiting for staff re-evaluation. Less than a minute of time will not disturb or interfere with staff work and easy administration will not affect patient compliance unless the patient's illness has impeded the patient's speech. Accordingly, this tool will be an appropriate health literacy tool to be used in a busy clinical health context ${ }^{[20]}$.

The four revised versions of the REALM demonstrated a reliable record when used in the health context in which they demonstrate continued satisfactory validity and reliability. For example, all revised versions have face validity because all test words are commonly used health terms ${ }^{[20,22]}$. The REALM words have been minimised from 125 words in the main REALM in 1991 to end up with seven words in the REALM-SF (2007). The latest version of WRAT-3 consists of 57 items, 15 letters and 42 words.

The concern about the REALM (125 words) and the 66 word, shortened version, is that both are unable to differentiate people with a health literacy level above ninth grade reading ability ${ }^{[4]}$. In addition, Bass III, et al. ${ }^{[16]}$ and Arozullah, et $a l .{ }^{[20]}$ agreed that the average time (two to three minutes) to administer the REALM could be too long in a very busy clinical setting such as in ED or in busy outpatient clinics, therefore recommending the REALM-SF. The NVS does have the ability to assess not only health literacy but also basic literacy, and where this is required may be useful to emergency nurses.

Emergency nurses and other health care professionals involved in the testing of a patient's level of literacy or health literacy need to be aware of how to test health literacy in a safe way ${ }^{[20,25,26]}$. Training on how to conduct a health literacy test is required. Training ED nurses to administer a health literacy test is an important step and will significantly improve 
the patient-clinician interaction as well as increase the patient's confidence in receiving information that is appropriate for their needs ${ }^{[20]}$. Training also is required to emphasise how to deliver the test in a non-threatening way to patients or clients ${ }^{[25]}$. For example Arozullah et al. ${ }^{[20]}$ suggested starting the REALM-SF with the statement "We are studying medical word reading in order to improve communication between healthcare providers and patients. Here is a list of medical words that may be difficult to read." (p. 1033). Online training courses are available at the Centre for Disease Control (http://www.cdc.gov/healthliteracy/training/) for health professionals and also at other sites relating to culture, health and ethnicity (http://www.hrsa.gov/culturalcompetence/index.html). Given the high proportion of the population that is reported to have limited health literacy, ED nurses may need to consider regular screening of patients presenting for triage.

Although the focus of this study is on the measurement of health literacy, ED nurses may actively implement strategies to improve the understanding of health information. Numerous educational approaches or interventions have been used to improve health outcomes for patients with low health literacy. Educational strategies such as considering the structure and design of information ${ }^{[42,43]}$, using numbers to indicate higher quality options ${ }^{[44]}$, pictorial representations ${ }^{[43]}$, using media presentations ${ }^{[44]}$, limiting the information and simplifying the readability of the information ${ }^{[42,44]}$, have all been used to improve health outcomes for patients with low health literacy. Emergency nurses can potentially design material for specific levels of education such as fifth grade reading ability (as recommended) for patients with limited health literacy level using available tools which measure readability ${ }^{[45]}$.

Health literacy tools discussed in this paper are more appropriate for culturally and linguistically diverse populations, and in fact most of these tools were established within populations speaking English as a second language ${ }^{[20,21,24]}$. The nominated tool has been trialled in a busy metropolitan hospital in Sydney, Australia. The Campbelltown Hospital Emergency Department, includes a large paediatric caseload, and serves health consumers from lower socio-economic backgrounds. Approximately (39\%) of the population speak English as a second language or were born in countries other than Australia ${ }^{[46]}$.

We have trained ED nurses to use the REALM-SF within a busy metropolitan emergency setting in Sydney as part of a clinical trial, testing an education program on fever management in children, for parents and carers with limited health literacy (Alqudah, Johnson, George \& Cowin, in press). This experience did highlight some important considerations when administering the REALM-SF. Patients were asked to read the list of words in the test, any word that is not attempted or mispronounced is considered an error. Patients with scores of six or more have a functional health literacy level, while patients scoring five or less were considered at risk of inadequate health literacy. After implementing the test in ED, emergency nurses recommended that the test be given in a private area.

\section{Conclusion and implications}

The ability of ED nurses to assess a patient's level of health literacy can help nurses to deliver health information in an accessible form for all patients. This review has confirmed that the REALM-SF is the preferred instrument for ED nurses. The REALM-SF is easy to administer and can be used quickly to assess both the patient and their carer's level of health literacy, and to tailor educational messages for patients and their carers. Emergency nurses should consider regular screening of patients within private areas within emergency where high levels of low health literacy may exist within local communities. Emergency nurses should also receive training in how to administer these tests in a non-threatening and accurate manner. The inclusion of REALM-SF within the normal practice of emergency nurses has the potential to assist in the delivery of comprehensible information for all patients, which may result in decreased re-presentations within emergency departments.

\section{References}

[1] Chew, L. D., Bradley, K. A., Boyko, E. J. Brief questions to identify patients with inadequate health literacy. Family Medicine. 2004; 11: 12 . 
[2] Herman, A., Young, K. D., Espitia, D., Fu, N., Farshidi, A. Impact of a health literacy intervention on pediatric emergency department use. Pediatric Emergency Care. 2009; 25(7): 434-8. PMid:19564810 http://dx.doi.org/10.1097/PEC.0b013e3181ab78c7

[3] Nielsen-Bohlman, L., Panzer, A., Kindig, D. Health literacy: A prescription to end confusion, Executive Summary: The National Academies Press; 2004. 1-18.

[4] Yin, H. S., Forbis, S. G., Dreyer, B. P. Health Literacy and Pediatric Health. Current Problems in Pediatric and Adolescent Health Care. 2007; 37(7): 258-86. PMid:17656324 http://dx.doi.org/10.1016/j.cppeds.2007.04.002

[5] Baker, D. W. The meaning and the measure of health literacy. Journal of General Internal Medicine. 2006; $21(8): 878-83$. PMid:16881951 http://dx.doi.org/10.1111/j.1525-1497.2006.00540.x

[6] Dunn, D. J. The sixth vital sign: health literacy assessment. The Florida nurse. 2010; 58(2): 12. Betz, C. L., Ruccione, K., Meeske, K., Smith, K., Chang, N. Health Literacy: A Pediatric Nursing Concern. Pediatric Nursing. 2008; 34(3): 9. PMid:20629455

[7] Rudd, R., Kirsch, I., Yamamoto, K. Literacy and Health in America. Princeton: Center for Global Assessment. 2004.

[8] UNESCO. Education for All Global Monitoring Report UNESCO Departament of Statistics. 2006: Available from: http://unesdoc.unesco.org/images/0014/001416/141639e.pdf.

[9] Barber, M. N., Staples, M., Osborne, R. H., Clerehan, R., Elder, C., Buchbinder, R. Up to a quarter of the Australian population may have suboptimal health literacy depending upon the measurement tool: Results from a population-based survey. Health Promotion International. 2009; 24(3): 252-61.

[10] Australian Bureau of Statistics. Adult Literacy and Life Skills Survey. 2006. PMid:19531559 http://dx.doi.org/10.1093/heapro/dap022

[11] Dillon, J. Australian teens' skills falling in maths, literacy. The Daily Telegraph 2010.

[12] Berkman, N. D., Sheridan, S. L., Donahue, K. E., Halpern, D. J., Viera, A., Crotty, K., et al. Health Literacy Interventions and Outcomes: An Updated Systematic Review. Evidence Report/Technology Assessment Number 199. 2011: Available from: http://www.ahrq.gov/downloads/pub/evidence/pdf/literacy/literacyup.pdf.

[13] Berry, A., Brousseau, D., Brotanek, J. M., Tomany-Korman, S., Flores, G. Why Do Parents Bring Children to the Emergency Department for Nonurgent Conditions? A Qualitative Study. Ambulatory Pediatrics. 2008; 8(6): 360-7.

[14] Coleman, C. Teaching health care professionals about health literacy: A review of the literature. Nursing Outlook. 2011; 59(2):70-8. PMid:19084785 http://dx.doi.org/10.1016/j.ambp.2008.07.001

[15] Bass III, P. F., Wilson, J. F., Griffith, C. H. A Shortened Instrument for Literacy Screening. Journal of General Internal Medicine. 2003; 18(12): 1036-8. PMid:21402202 http://dx.doi.org/10.1016/j.outlook.2010.12.004

[16] Adams, R. J., Stocks, N. P., Wilson, D. H., Hill, C. L., Gravier, S., Kickbusch, I., et al. Health literacy: A new concept for general practice? Australian Family Physician. 2009; 38(3): 144-7. PMid:14687263 http://dx.doi.org/10.1111/j.1525-1497.2003.10651.x

[17] Davis, T. C., Long, S. W., Jackson, R. H., Mayeaux, E. J., George, R. B., Murphy, P. W., et al. Rapid estimate of adult literacy in medicine: A shortened screening instrument. Family Medicine. 1993; 25(6): 391-5. PMid:19283256

[18] Parker, R. M., Baker, D. W., Williams, M. V., Nurss, J. R. The test of functional health literacy in adults: A new instrument for measuring patients' literacy skills. Journal of General Internal Medicine. 1995; 10(10): 537-41. PMid:8349060

[19] Arozullah, A. M., Yarnold, P. R., Bennett, C. L., Soltysik, R. C., Wolf, M. S., Ferreira, R. M., et al. Development and validation of a short-form, Rapid Estimate of Adult Literacy in Medicine. Medical Care. 2007; 45(11): 1026-33. PMid:8576769 http://dx.doi.org/10.1007/BF02640361

[20] Davis, T. C., Crouch, M. A., Long, S. W., Jackson, R. H., Bates, P., George, R. B., et al. Rapid assessment of literacy levels of adult primary care patients. Family Medicine. 1991; 23(6): 433. PMid:18049342 http://dx.doi.org/10.1097/MLR.0b013e3180616c1b

[21] Davis, T. C., Wolf, M. S., Arnold, C. L., Byrd, R. S., Long, S. W., Springer, T., et al. Development and validation of the Rapid Estimate of Adolescent Literacy in Medicine (REALM-Teen): A tool to screen adolescents for below-grade reading in health care settings. Pediatrics. 2006; 118(6): 1707-14 PMid:1936717

[22] Hanson-Divers, E. C. Developing a medical achievement reading test to evaluate patient literacy skills: A preliminary study. Journal of Health Care for the Poor and Underserved. 1997; 8(1): 56-69. PMid:17142495 http://dx.doi.org/10.1542/peds.2006-1139

[23] Weiss, B. D., Mays, M. Z., Martz, W., Castro, K. M., DeWalt, D. A., Pignone, M. P., et al. Quick assessment of literacy in primary care: The newest vital sign. Annals of Family Medicine. 2005; 3(6): 514-22. PMid:9019026 http://dx.doi.org/10.1353/hpu.2010.0304

[24] Wallace, L. S., Rogers, E. S., Roskos, S. E., Holiday, D. B., Weiss, B. D. Brief report: screening items to identify patients with limited health literacy skills. Journal of general internal medicine. 2006; 21(8): 874-7. PMid:16338915 http://dx.doi.org/10.1370/afm.405

[25] Davis, T. C., Michielutte, R., Askov, E. N., Williams, M. V., Weiss, B. D. Practical Assessment of Adult Literacy in Health Care. Health Education and Behavior. 1998; 25(5): 613-24. PMid:16881950 PMCid:PMC1831582 http://dx.doi.org/10.1111/j.1525-1497.2006.00532.x 
[26] Powell, G., Moore, D., Callaway, B. A concurrent validity study of the Woodcock Word Comprehension Test. Psychology in the Schools.1981; 18 (1): 24-7. PMid:9768381 http://dx.doi.org/10.1177/109019819802500508

[27] Johnstone, B., Wilhelm, K. The longitudinal stability of the WRAT-R Reading subtest: Is it an appropriate estimate of premorbid intelligence? Journal of the International Neuropsychological Soci. 1996; 6: 282-5. http://dx.doi.org/10.1002/1520-6807(198101)18:1<24::AID-PITS2310180106>3.0.CO;2-S

[28] Wilkinson, G.S. WRAT 3: Wide Range AchivementTest. Test Review. 1993; 5 (1): 61-6. http://dx.doi.org/10.1017/S1355617700001296

[29] Yost, K.J., Webster, K., Baker, D. W., Choi, S.W., Bode, R. K., Hahn, E. A. Bilingual health literacy assessment using the Talking Touchscreen/la Pantalla Parlanchina: Development and pilot testing. Patient education and counseling. 2009; 75(3): $295-301$.

[30] Hahn, E. A., Choi, S. W., Griffith, J. W., Yost, K. J., Baker, D. W. Health Literacy Assessment Using Talking Touchscreen Technology (Health LiTT): A New Item Response Theory-Based Measure of Health Literacy. Journal of Health Communication. 2011; 16(sup3): 150-62. PMid:19386462 http://dx.doi.org/10.1016/j.pec.2009.02.020

[31] Levin-Zamir, D., Lemish, D., Gofin, R. Media Health Literacy (MHL): development and measurement of the concept among adolescents. Health Education Research. 2011; 26(2): 323.

[32] Baron-Epel, O., Balin, L., Daniely, Z., Eidelman, S. Validation of a Hebrew health literacy test. Patient education and counseling. 2007; 67(1): 235-9. PMid:21422003 http://dx.doi.org/10.1093/her/cyr007

[33] Lee, S. Y. D., Bender, D.E., Ruiz, R. E., Cho, Y. I. Development of an Easy-to-Use Spanish Health Literacy Test. Health Services Research. 2006; 41(4p1): 1392-412. PMid:17386994 http://dx.doi.org/10.1016/j.pec.2007.02.005

[34] Pleasant, A. Coming to consensus on health literacy measurement: An online discussion and consensus-gauging process. Nursing Outlook. 2011; 59(2):95-1 06.

[35] Tadros, S., Wallis, D., Sharland, M. Lack of use for advice by parents results in increasing attendance to the paediatric emergency department. Archives of Disease in Childhood. 2009; 94(6): 483-4.

[36] DeWalt, D. A., Berkman, N. D., Sheridan, S., Lohr, K. N., Pignone, M. P. Literacy and health outcomes: A systematic review of the literature. Journal of General Internal Medicine. 2004; 19(12): 1228-39. PMid:19460930 http://dx.doi.org/10.1136/adc.2008.155598

[37] Adams, R. J., Appleton, S. L., Hill, C.L., Dodd, M., Findlay, C., Wilson, D. H. Risks associated with low functional health literacy in an Australian population. The Medical journal of Australia. 2009; 191(10): 530-4. PMid:15610334 http://dx.doi.org/10.1111/j.1525-1497.2004.40153.x

[38] Pfizer. The Newest Vital Sign: A Health Literacy Assessment Tool for Patient Care and Research. 2010 [cited 2010.20.09]; Available from: http:/www.pfizerhealthliteracy.com/asset/pdf/NVS_Eng/files/nvs_flipbook_english_final.pdf. PMid:19912083

[39] Felton, R. H., Naylor, C. E., Wood, F.B. Neuropsychological profile of adult dyslexics. Brain and Language. 1990; $39(4)$ : $485-97$.

[40] Hudson, P. V., Marshall, A. P. Extending the nursing role in Emergency Departments: Challenges for Australia. Australasian Emergency Nursing Journal. 2008; 11(1): 39-48. http://dx.doi.org/10.1016/0093-934X(90)90157-C

[41] Greene, J., Peters, E., Mertz, C., Hibbard, J. H. Comprehension and choice of a consumer-directed health plan: an experimental study. The American journal of managed care. 2008; 14(6): 369. http://dx.doi.org/10.1016/j.aenj.2007.11.003

[42] Peters, E., Dieckmann, N., Dixon, A., Hibbard, J. H., Mertz, C. Less is more in presenting quality information to consumers. Medical Care Research and Review. 2007; 64(2): 169-90. PMid:18554075

[43] Kang, E. Y., Fields, H. W., Kiyak, A., Beck, F. M., Firestone, A. R. Informed consent recall and comprehension in orthodontics: traditional vs improved readability and processability methods. American Journal of Orthodontics and Dentofacial Orthopedics. 2009; 136(4): 488. PMid:17406019 http://dx.doi.org/10.1177/10775587070640020301

[44] Nottingham, T. U. O. How to use the SMOG Calculator 2010 [cited 01/01/2011]; Available from: http://www.niace.org.uk/misc/SMOG-calculator/smogcalc.php PMid:19815144 http://dx.doi.org/10.1016/j.ajodo.2009.04.014

[45] Sydney South West Area Health. (2005). A Health Profile of Sydney South West-A status report describing the population, their health and the services provided for Sydney South West Area Health Service 2005; Available from: http://www.sswahs.nsw.gov.au/agm/DemProfile.pdf 